\title{
TREATMENT OF JUXTA-ARTICULAR GIANT CELL TUMOURS WITH CUSTOM MADE MEGAPROSTHESIS
}

\author{
Manoj Kumar R1, Ibad Sha I', Ajin Edwin ${ }^{3}$ \\ ${ }^{1}$ Additional Professor, Department of Orthopaedics, Government Medical College, Trivandrum. \\ ${ }^{2}$ Resident, Department of Orthopaedics, Government Medical College, Trivandrum. \\ ${ }^{3}$ Resident, Department of Orthopaedics, Government Medical College, Trivandrum.
}

\section{ABSTRACT}

\section{BACKGROUND}

Juxta-articular giant cell tumours are common and pose a special problem of reconstruction after tumour excision. This article analyses the functional outcome after resection of juxta-articular giant cell tumours around the Knee, Hip and Shoulder replacement by custom mega-prosthetic arthroplasty.

\section{MATERIALS AND METHODS}

Total of seven patients with juxta-articular giant cell tumours with mean age of 30.8 years underwent resection and replacement by custom mega-prosthetic arthroplasty during the period from 2013 to 2016.

\section{RESULTS}

Six patients had excellent result, one had good result as per Enneking criteria. There was no incidence recurrence, periprosthetic fractures, infections or aseptic loosening during the study period. There was no case of metastasis or death.

\section{CONCLUSION}

To conclude custom mega prosthetic arthroplasty is effective in achieving the desired aim of reconstruction of joint with good functional results and least complications in selected patients.

\section{KEYWORDS}

Custom Mega-Prosthesis, Juxta-articular Giant Cell Tumour, Outcome.

HOW TO CITE THIS ARTICLE: Kumar MR, Sha II, Edwin A. Treatment of juxta-articular giant cell tumours with custom made megaprosthesis. J. Evolution Med. Dent. Sci. 2017;6(39):3147-3150, DOI: 10.14260/Jemds/2017/679

\section{BACKGROUND}

Giant Cell Tumour (GCT) of bone is one of the commonest benign bone tumours encountered by an orthopaedic surgeon that are aggressive, potentially malignant lesions. The incidence of GCT among Asian population is higher compared to the Western population and may contribute for $20 \%$ of all skeletal neoplasms. ${ }^{1,2} 80$ percent of the GCT have a benign course with a local recurrence rate varying between $10 \%$ to $50 \%$; out of all about $10 \%$ cases undergo malignant transformation through their recurrences. Pulmonary metastases can occur in $1 \%-4 \%$, even in case of a benign histology. 3,4

The ideal goal in the treatment of GCT is to eradicate the tumour without sacrificing the joint. Wide resection is the treatment of choice, especially in patients presenting with pathological fractures, recurrences and high-grade tumours, doubtful of malignancy. ${ }^{1}$ Following en bloc resection of major joints need reconstruction of joints either using allograft or custom mega-prosthesis to achieve good functional outcome. Current recurrence rates between 10\% - 20\% with meticulous curettage and extension of tumour removal using mechanised burrs and adjuvant therapy are a vast

Financial or Other, Competing Interest: None.

Submission 21-04-2017, Peer Review 07-05-2017,

Acceptance 10-05-2017, Published 15-05-2017.

Corresponding Author:

Dr. Manoj Kumar R,

Additional Professor,

Department of Orthopaedics,

Government Medical College,

Trivandrum.

E-mail:drmanojkrr67@yahoo.com

DOI: $10.14260 /$ jemds $/ 2017 / 679$ improvement on the historically reported recurrence rates of $50 \%$ - $60 \%$ with curettage alone.5,6

This article analyses the functional outcomes after resection of juxta-articular GCTs and reconstruction by custom mega-prosthetic arthroplasty.

\section{MATERIALS AND METHODS}

\section{Sample Size}

Since juxta-articular GCT is rare in incidence, all cases in the study period were taken as the sample size.

Total of seven patients with juxta-articular GCTs around the hip, knee and shoulder were treated with custom prosthesis. Only those patients treated using custom made mega-prosthesis were included in the study. The patients with juxta-articular GCTs around the hip and knee who underwent resection and reconstruction by custom megaprosthetic arthroplasty during the period 2013 to 2016 were analysed in this study. Three patients were males and four were females (Ratio of 3:4). The age group of patients was average of $40 \mathrm{yrs}$. (Range 30 to $50 \mathrm{yrs}$.). Five patients had giant cell tumour around the knee, one patient had giant cell tumour in neck of femur and one in the head of humerus. All patients were histologically proven by Fine Needle Aspiration Cytology (FNAC) or open biopsy. Proximal femur was involved in one patient [Figure 1], distal femur in three, proximal humerus in one [Figure 2] and proximal tibia in two patients [Figure 3]. Surgical staging was done according to the Enneking's staging system. All patients were in Enneking Stage 3 . 


\section{The Prosthesis Design}

The custom mega-prostheses made up of stainless steel or titanium, manufactured in Delhi, India were used.

\section{Proximal Femoral Prosthesis}

The basic design of the prosthesis is a femoral head component, which is bipolar with diameter of $47 \mathrm{~mm}$, a proximal femoral shaft length of $70 \mathrm{~mm}$ with neck shaft angle being 135 degrees, a stem of length $10 \mathrm{~cm}$.

\section{Distal Femoral and Proximal Tibial Prosthesis}

These custom mega-prostheses are hinged designs containing a femoral condylar component, a pivot pin, a thrust-bearing pad made of ultra-high molecular weight polyethylene and a tibial component. Proximally, the prosthesis having an angulation laterally by $6^{\circ}$ to resemble the normal valgus angle of the femur. The function of the thrust-bearing polyethylene pad is to allow a flexion of $150^{\circ}$ between the femoral and tibial components. The ultra-high molecular weight polyethylene-bearing pad serves to relocate the load transmitted during weight bearing. Measurement are calculated with the help of radiography and Magnetic Resonance Imaging (MRI).

\section{Surgical Technique}

\section{For GCT of Neck of Femur}

The patient was positioned in left lateral position on table, posterior Moor's approach extended distally along the lateral aspect of the thigh encircling the biopsy scar was put. Complete resection of the tumour bearing part and replacement with cemented custom mega-prosthesis was done [Figure 4]. Proximally, the prosthesis was kept at an anteversion of 15 degrees. Vastus lateralis muscle was attached to the hook of the prosthesis with non-absorbable sutures. Adductor tenotomy was done to compensate weak abductors. Wound was closed after achieving meticulous homeostasis. Quadriceps strengthening exercises were started from the second post-operative day. Protected weight bearing with the help of walker was begun after suture removal and patient was instructed to keep limbs in wide abduction and advised not to squat at the time of discharge from the hospital.

For juxta-articular GCT around the knee, extended medial parapatellar approach encircling the biopsy scar was used. Tumour dissection was carried out without damaging the neuromuscular structures. We used the technique of sleeve resection of quadriceps musculature. The excision removes a portion of the vastus lateralis, medialis and intermedius, but preserves enough musculature to provide soft-tissue coverage for the prosthesis and retains adequate extension power. Following reaction of tumour reconstruction with custom mega-prosthetic arthroplasty was carried out. Postoperative x-rays were taken [Figure 5]. Quadriceps strengthening exercises were started from the 2nd postoperative day. Knee bending was started after 3 weeks.

\section{RESULTS}

The minimum follow-up of all patients was done for 18 months and were evaluated according to we determined clinical function according to the Musculoskeletal Tumour Society Rating Score (MTSRS) advocated by Enneking in 1985 and revised in 1993. In this system, parameters are taken into account that are pertinent to reconstructions involving the proximal leg, knee or distal thigh. The seven parameters, rated excellent, good, fair or poor include active range of motion at the knee, pain, joint stability (varus/valgus), joint deformity (varus/valgus, flexion contracture), strength, functional activity and emotional acceptance. An overall rating is achieved by combining the individual rating on each parameter. For instance, to have a good result six of the seven primary factors must rate good or better, the seventh may be fair or poor. In our study, excellent results were obtained in all the patients except one who had good result without any incidence recurrence, periprosthetic fractures, infections or aseptic loosening during the study period. There was no case of metastasis or death. [Figure 6, 7].
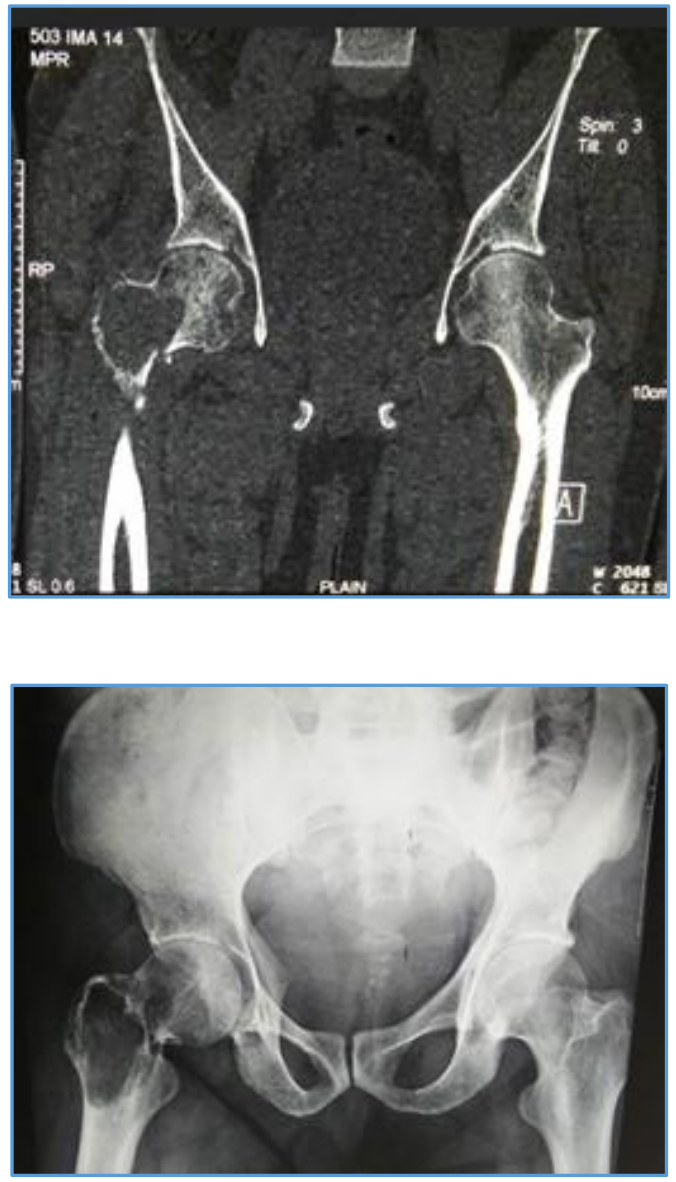

Figure 1

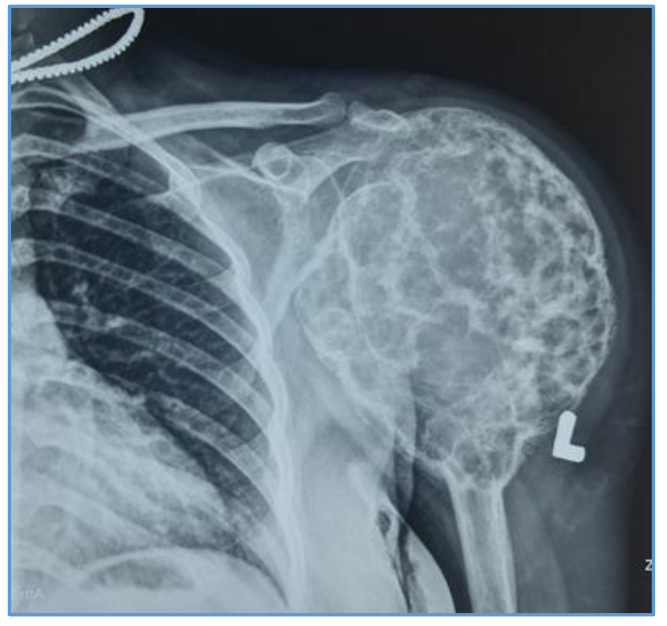

Figure 2 


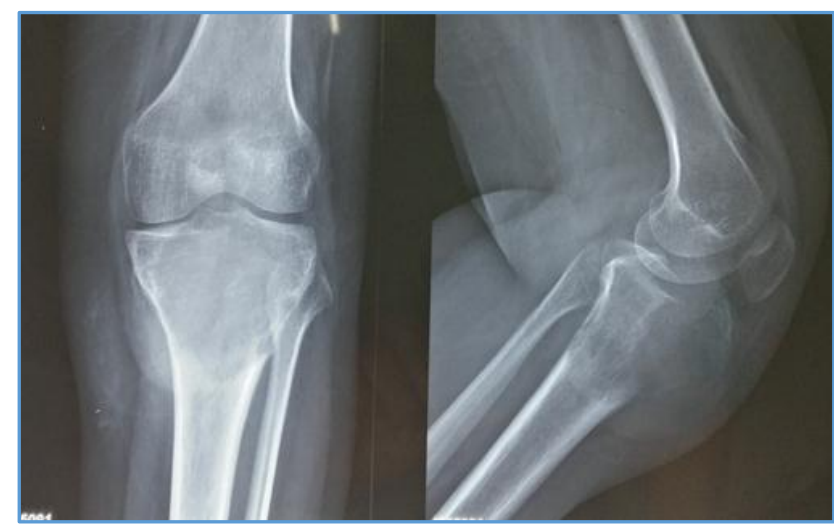

Figure 3

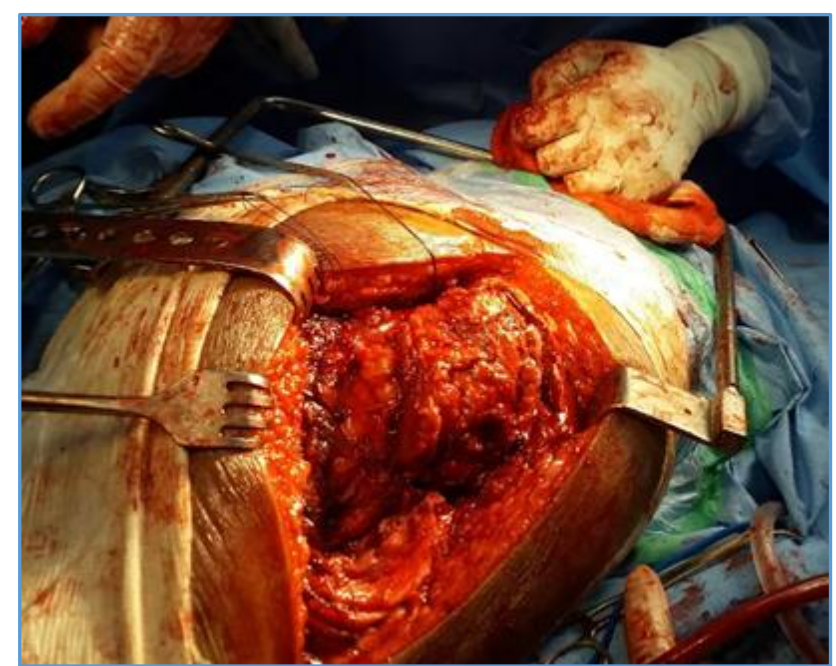

Figure 4

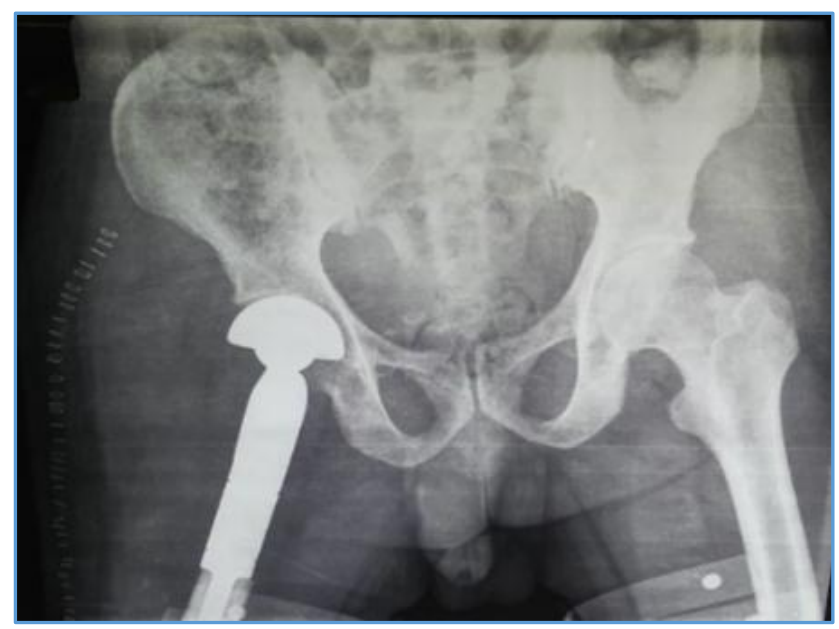

Figure 5

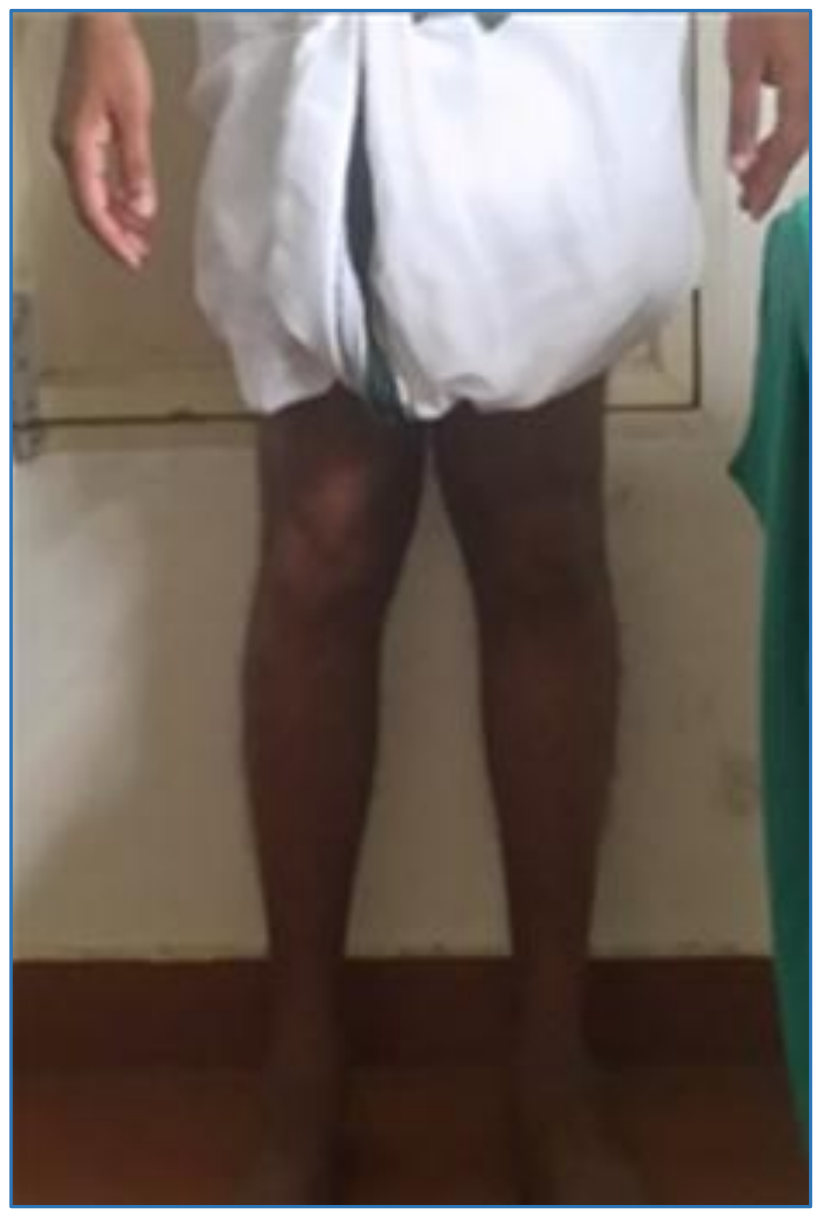

Figure 6

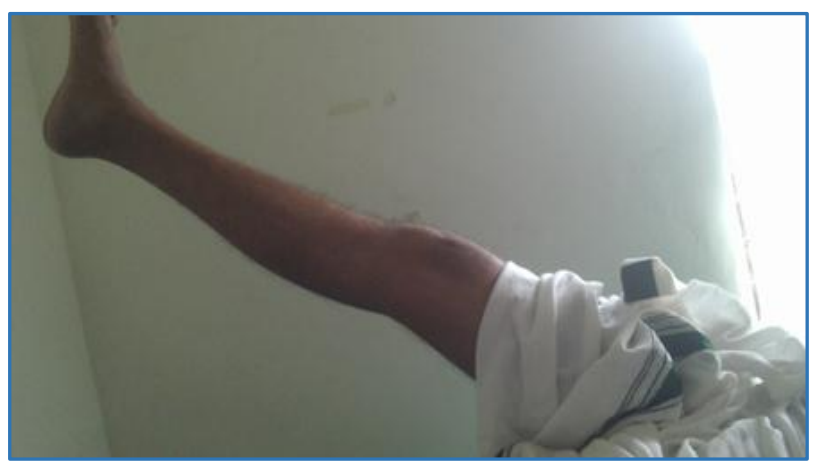

Figure 7

\section{DISCUSSION}

The treatment of GCTs is directed mainly towards the local control of the tumour without sacrificing joint function. This has been traditionally achieved by intralesional curettage along with autograft reconstruction packing the cavity of excised tumour regardless of the extent of curettage, intralesional excision leaves microscopic disease in the bone and hence a recurrence rate as high as $60 \%$ has been reported. Recently with the help of modern instruments such as high power burr, pulsatile jet lavage system, headlamp and dental mirror combined with multiple angled curettes have decreased the recurrence rate to $20 \%$. Recurrence has been reported instead of the use of adjuvants such as phenol and hydrogen peroxide. Cryosurgery using liquid nitrogen will reduce recurrence, but is associated with high incidence of local wound and bone complications. ${ }^{7}$ 
Adequate removal of tumour seems to be a more important predictive factor for the outcome of surgery. This is achieved by wide excision, but it leaves large bone defects. Methyl methacrylate cement, used to fill the defect is though strong in compression is relatively weak when subjected to shear and torsional forces. Moreover, they can lead to degeneration of articular cartilage in subchondral lesions. Autografts can also be used to fill the defect, but limiting factor is the quantity and donor site morbidity. Allograft is expensive and requires a bone bank and can lead to infection, fracture, non-union and joint instability. Bone lengthening is a time-consuming procedure and being close to joint may not produce desired outcome. Arthrodesis has complications including a high risk of delayed or non-union and fractures and also sacrifice function. The cosmetic outcome of rotation plasty is a serious disadvantage due to which we have only historical importance now. 8,9

Hence, custom mega-prosthetic arthroplasty has become the method of choice after bone tumour resection at the knee. It is the primary modality in the treatment of aggressive bone tumours of lower limb. Grade 3 tumours are characterised by Fuzzy borders and cortical breach, joint salvage is not possible. The use of custom mega-prosthesis is a simple and technically superior method of feeling the bone defects in benign aggressive lesions with pathological fractures and where skeletal reconstruction is difficult after intralesional curettage. The advantages of custom made mega-prosthetic arthroplasty are least rates of recurrence, immediate resumption of knee joint function with early ambulation. The possible complications include flap necrosis, secondary infection, aseptic loosening and breakage.

\section{CONCLUSION}

To conclude, achieving complete removal of the tumour tissue and preserving a functional extremity at the same time proves to be a difficult job. Difficulties in the local control of high-grade giant cell tumours as well as high rate of local recurrence following initial surgery have led to the emerging of custom mega-prosthesis as the treatment of choice in selected cases. By using the technique of Limb Salvage by custom mega-prosthesis, satisfactory oncological and functional outcomes have been achieved in our patients.

\section{REFERENCES}

[1] Sung HW, Kuo DP, Shu WP, et al. Giant-cell tumor of bone: analysis of two hundred and eight cases in Chinese patients. J Bone Joint Surg Am 1982;64(5):755-61.

[2] Settakorn J, Lekawanvijit S, Arpornchayanon 0, et al. Spectrum of bone tumors in Chiang Mai university hospital, Thailand according to WHO classification 2002: a study of 1,001 cases. J Med Assoc Thai 2006;89(6):780-7.

[3] Enneking WF. Bristol-Myers/Zimmer orthopaedic symposium. Limb salvage in musculoskeletal oncology. Modification of the system for functional evaluation of surgical management of musculoskeletal tumors; New York: Churchill Livingstone 1987: 626-39.

[4] Natarajan MV, Annamalai K, Williams S, et al. Limb salvage in distal tibial osteosarcoma using a custom mega prosthesis. Int Orthop 2000;24(5):282-4.

[5] Vidyadhara S, Rao SK. A novel approach to juxtaarticular aggressive and recurrent giant cell tumours: resection arthrodesis using bone transport over an intramedullary nail. Int Orthop 2007;31(2):179-84.

[6] Kawai A, Lin PP, Boland PJ, et al. Relationship between magnitude of resection, complication, and prosthetic survival after prosthetic knee reconstructions for distal femoral tumors. J Surg Oncol 1999;70(2): 109-15.

[7] Hillmann A, Hoffmann C, Gosheger G, et al. Malignant tumor of the distal part of the femur or the proximal part of the tibia: endoprosthetic replacement or rotationplasty. Functional outcome and quality-of-life measurements. J Bone Joint Surg Am 1999;81(4): 462-8.

[8] Clohisy DR, Mankin HJ. Osteoarticular allografts for reconstruction after resection of a musculoskeletal tumor in the proximal end of the tibia. J Bone Joint Surg Am 1994;76(4):549-54.

[9] Mittermayer F, Krepler P, Dominkus M, et al. Longterm followup of uncemented tumor endoprostheses for the lower extremity. Clin Orthop Relat Res 2001;388:167-77. 